\title{
Nocturnal blood pressure during apnoeic and ventilatory periods in patients with obstructive sleep apnoea
}

\author{
Ye. Tun, S. Okabe, W. Hida, H. Kurosawa, M. Tabata, Y. Kikuchi, K. Shirato
}

\begin{abstract}
Nocturnal blood pressure during apnoeic and ventilatory periods in patients with obstructive sleep apnoea. Ye. Tun, S. Okabe, W. Hida, H. Kurosawa, M. Tabata, Y. Kikuchi, K. Shirato. (C) ERS Journal Ltd 1999.

ABSTRACT: The exact nature of asleep blood pressure in relation to awake blood pressure is still unclear in patients with obstructive sleep apnoea. This study aimed: 1) to investigate the asleep blood pressure in both apnoeic and ventilatory periods; 2 ) to determine the diurnal and nocturnal factors correlated with the changes in blood pressure from apnoea to ventilatory periods during sleep.

Thirty-two patients, newly diagnosed as moderate to severe obstructive sleep apnoea with a standard nocturnal polysomnography, were enrolled. The blood pressure was monitored by using the noninvasive continuous monitoring method during polysomnographic study.

The mean blood pressures in ventilatory periods during nonrapid eye movement (NREM) and rapid eye movement (REM) sleep were $117.5 \pm 17.9 \mathrm{mmHg}$ and $128.8 \pm$ $21.9 \mathrm{mmHg}$, and those in apnoea periods were $94.5 \pm 15.4 \mathrm{mmHg}$ and $102.7 \pm 19.0$ mmHg. The average blood pressure during NREM sleep $(103.0 \pm 16.1 \mathrm{mmHg})$ was higher than the awake blood pressure $(97.0 \pm 15.7 \mathrm{mmHg})$. The blood pressure during REM sleep was greater than that during NREM sleep. The changes in the nocturnal blood pressure from apnoea to ventilatory periods were inversely correlated with the age and nocturnal mean nadir saturation.

In conclusion, patients with obstructive sleep apnoea have higher asleep blood pressure than awake blood pressure.

Eur Respir J 1999; 14: 1271-1277.
\end{abstract}

\author{
First Dept of Internal Medicine, Tohoku \\ University School of Medicine, 1-1 Seir- \\ yo-machi, Aoba-ku, Sendai, 980-8574 \\ Japan. \\ Correspondence: K. Shirato \\ First Dept of Internal Medicine \\ Tohoku University School of Medicine \\ 1-1 Seiryo-machi, Aoba-ku, Sendai, 980- \\ 8574 Japan \\ Fax: 81227177156
}

Keywords: Age

desaturation

haemodynamics

nonrapid eye movement sleep

rapid eye movement sleep

Received: February 161999

Accepted after revision June 111999
Obstructive sleep apnoea (OSA) is commonly associated with abrupt, transient elevations of the systemic arterial blood pressure immediately following the release of the upper airway obstruction during sleep $[1,2]$. In an earlier study using intra-arterial monitoring, patients with OSA who were normotensive in the daytime showed apnoea-related cyclical rises in the systemic blood pressure exceeding $200 \mathrm{mmHg}$ (systolic) and reaching or exceeding $120 \mathrm{mmHg}$ (diastolic) while asleep [2]. This finding may suggest that patients with OSA have a higher nocturnal blood pressure than that during the awake period.

Patients with OSA experience many cardiovascular complications such as arrhythmia, cardiac hypertrophy, heart failure, myocardial infarction, and cerebrovascular diseases [3-6]. VERDECCHIA et al. [7] reported in patients with essential hypertension that a blunted nocturnal fall in blood pressure on ambulatory monitoring was associated with subsequent cardiovascular morbidity. Another study also showed that hypertensive patients with higher nocturnal blood pressure had target organ damage which was greater than that of other hypertensive patients [8]. It is therefore assumed that the high nocturnal blood pressure might contribute to the high prevalence of cardiovascular complications in patients with OSA.

Most studies using $24 \mathrm{~h}$-ambulatory blood pressure monitoring, however, reported only a nondipping during sleep, and the nocturnal blood pressure was found to still be lower than the mean day time blood pressure in patients with OSA [9-11]. Because of rapid oscillations of blood pressure during apnoea periods, the value obtained by the 24 h-ambulatory method may be underestimated. Thus, to detect such rapid changes of blood pressure, invasive intra-arterial or noninvasive continuous monitoring should be used. However, because of the difficulty of these methods, data available for comparison of nocturnal blood pressure to awake blood pressure measured by such methods are still few.

Regarding the mechanisms of the postapnoeic blood pressure elevation, the progressive rise in systemic blood pressure was correlated with the severity of nocturnal desaturation $[12,13]$, but some investigators reported that the apnoea duration was related to the blood pressure elevation in individual patients [14]. Most of these studies were performed in only a small number of patients. Since there is wide subject-to-subject variation in the desaturation and apnoea length, the nature of the relation of desaturation and apnoea length to the nocturnal blood pressure oscillation on an inter-individual basis is still unclear. Moreover, the relation of age, body mass index, pre-existing awake blood pressure and awake respiratory chemosensitivity to the nocturnal blood pressure oscillation have not been evaluated yet. To predict the nocturnal blood pressure variability, it is important to examine the diurnal and nocturnal factors with which the nocturnal blood pressure oscillations are to be correlated. 
In this study the authors examined the nocturnal blood pressure in the first period of non-rapid eye movement (NREM) and rapid eye movement (REM) sleep by using the noninvasive continuous monitoring method, and compared it to the awake blood pressure in 32 patients with OSA, and also evaluated the correlation of the diurnal and nocturnal factors to the apnoea-related blood pressure oscillations in these patients.

\section{Patients and methods}

\section{Patients}

Initially, 45 consecutive patients with moderate to severe OSA were collected, but 13 patients were excluded because REM sleep was not achieved. Therefore, in 32 patients both NREM and REM sleep periods could be studied. The blood pressure data for these patients were collected and processed. All were newly diagnosed as OSA and had a history of habitual snoring and excessive day time sleepiness. No patient had been treated with nasal continuous positive airway pressure (CPAP) or by any other treatments for sleep apnoea previously. Patients who needed to continue antihypertensive treatment, or who had uncontrolled diabetes mellitus, thyroid disorders or other major medical illnesses were excluded from the study. Thirteen of 32 patients had a history of hypertension and only 6 of them had taken antihypertensive drugs. All antihypertensive drugs were tapered and stopped 1 week before blood pressure measurement. Written informed consent to the protocol (which had received prior approval from the Human Research Committee of the Tohoku University School of Medicine, Sendai, Japan was obtained from each subject before the start of this study.

\section{Measurements}

Nocturnal polysomnography. A control overnight sleep study was carried out by using standard polysomnographic equipment including electroencephalography (EEG; C4/A1, C3/A2), electro-oculography (EOG), submental electromyography (EMG), and electrocardiography (ECG) with surface electrodes, air flow at nose and mouth with thermistors, respiratory movements of the rib cage and abdomen with inductive plethysmography belts (Respitrace; Ambulatory Monitoring, Ardsley, NY, USA) and arterial oxyhaemoglobin saturation $\left(\mathrm{Sa}, \mathrm{O}_{2}\right)$ with a finger pulse oximeter (Biox 3700; Ohmeda, Boulder, CO, USA). This nocturnal sleep study was conducted in a darkened quiet room. All variables were recorded on an eight channel thermal chart recorder (model 360; NEC Sanei, Tokyo, Japan) and a personal computer using MacLab with chart 3.5 system (115-120/VAC, Kipping, Australia). From this control night, the apnoea-hypopnoea index (AHI) and lowest $\mathrm{Sa}_{\mathrm{a}} \mathrm{O}_{2}$ were calculated as an indication of the severity of sleep apnoea for each patient.

An apnoea episode was defined as a cessation of airflow lasting $\geq 10 \mathrm{~s}$, while hypopnoea was defined as either a $50 \%$ decrease in airflow from baseline or a partial reduction in airflow with a decline in $\mathrm{Sa}_{\mathrm{a}} \mathrm{O}_{2}$ of at least $4 \%$. Obstructive apnoea was classified by using the respitrace and airflow signals. Sleep stages were determined according to international standard criteria [15].
Nocturnal blood pressure measurement. On the following night, an overnight blood pressure measurement was conducted in the same way as on the control night described above. Systemic blood pressure was measured continuously by a noninvasive photoelectric plethysmographic monitor (Finapres model 2300; Ohmeda, Englewood, CO, USA) and recordings were made from a cuff positioned on the second phalanx of the middle finger of the left hand which was kept at a hydrostatic level similar to that of the heart throughout the period of measurement.

All parameters were recorded in the same system as on the control night. Because these patients were moderate to severe OSA the investigators could find minimal or no stage 3 and 4 sleep in the EEG analysis. Moreover, most patients experienced discomfort at the finger when the blood pressure monitor was applied for $>3-4 \mathrm{~h}$ during sleep. To control for the effects of different stages of sleep, the blood pressure data during the first period of stage 2 NREM sleep and the first period of REM sleep were selected for data analysis. The blood pressure during 10 min while awake was averaged for the awake blood pressure. During sleep the authors calculated the average systolic and diastolic blood pressure at the time of apnoea and ventilation for each episode using an average of 60 episodes (31.4 $\mathrm{min}$ ) in a NREM period and 20 episodes (14.8 $\mathrm{min}$ ) in a REM period in each patient. The average systolic and diastolic blood pressure, referred to as the nocturnal blood pressure, was calculated for all of the first period of NREM sleep and for all of the first period of REM sleep. Mean arterial blood pressure (MAP) was calculated by one third systolic blood pressure plus two thirds diastolic blood pressure. Although the mean blood pressure calculated is affected by heart rate changes, it approximates the real mean blood pressure [16]. The change in mean blood pressure was calculated as the difference between the mean blood pressure of the apnoea and that of the ventilatory period. Any artefacts caused by recording disturbances and hand movements were excluded from the calculation. The mean nadir $\mathrm{Sa}, \mathrm{O}_{2}$ was taken by averaging the nadir $\mathrm{Sa}_{\mathrm{a}} \mathrm{O}_{2}$ during apnoea periods. The apnoea duration was calculated from the end of the forecoming expiration to the beginning of the succeeding ventilation, and then the ventilatory duration was taken from the end of one apnoea to the start of the next apnoeic episode.

Chemosensitivity tests. Chemosensitivity tests were performed on the day following the nocturnal blood pressure measurement with the patients awake and comfortably seated in a quiet room. The ventilatory and mouth occlulusion pressure $\left(P_{0.1}\right)$, responses to hypoxia and hypercapcapnia were measured using the method of READ [17] and REBUCK and CAmpBell [18], respectively. Ventilatory flow was measured using a Fleisch pneumotachograph (Chest Corp., Tokyo, Japan), and end-tidal partial pressure of carbon dioxide $\left(\mathrm{PCO}_{2}\right)$ and end-tidal partial pressure of oxygen $\left(\mathrm{PO}_{2}\right), P 0.1$, and $\mathrm{S}_{\mathrm{a}} \mathrm{O}_{2}$ were also recorded. The end-tidal $\mathrm{PCO}_{2}$ and end-tidal $\mathrm{PO}_{2}$ were measured by mass spectrometry (WSMR-1400; Westron, Chiba, Japan). The ventilatory and $P_{0.1}$ response to hypoxia and hypercapnia were expressed as the slope of the regression line of ventilation $\left(V^{\prime} \mathrm{E}\right)$ and $P 0.1$ against $S_{\mathrm{a}, \mathrm{O}_{2}}$ (change $(\Delta) V^{\prime} \mathrm{E} /$ $\Delta \mathrm{Sa}_{2} \mathrm{O}_{2}$ and $\left.\Delta P 0.1 / \Delta \mathrm{Sa}_{2} \mathrm{O}_{2}\right)$ and end-tidal $P \mathrm{CO}_{2}\left(P \mathrm{ET}, \mathrm{CO}_{2}\right)$ $\left(\Delta V^{\prime} \mathrm{E} / \Delta P \mathrm{ET}, \mathrm{CO}_{2}\right.$ and $\left.\Delta P 0.1 / \Delta P \mathrm{CO}_{2}\right)$ respectively. 
Spirometry and arterial blood gas analysis. Spirometry including vital capacity (VC), forced expiratory volume in one second (FEV1) and flow-volume curve were measured with a rolling-seal spirometer (Fudac-70s; Fukuda, Tokyo, Japan). Arterial blood gas analysis including oxygen tension in arterial blood $\left(\mathrm{Pa}_{\mathrm{a}} \mathrm{O}_{2}\right)$, carbon dioxide tension in arterial blood $\left(\mathrm{Pa}_{\mathrm{a}} \mathrm{CO}_{2}\right), \mathrm{pH}$, and $\mathrm{HCO}_{3}{ }^{-}$was performed at the same time as the pulmonary function test.

Electrocardiography, echocardiography and chest radiograph. All patients were investigated with a standard 12 lead ECG, ambulatory ECG (Holler monitoring), and M-mode and two directional echocardiography to detect arrhythmia, the cardiac structure and function. A chest radiograph (posteroanterior) was taken for determining the cardiothoracic ratio.

\section{Statistical analysis}

Statistical analysis was performed by the statview 2 statistical package for Macintosh (Abacus Concepts Inc., Berkeley, CA, USA). Analysis of variances (ANOVA) and paired t-test as a post-hoc test were used to compare average blood pressure in each period. The correlations of changes in mean blood pressure from apnoea periods to ventilation periods as a dependent variable to other diurnal and nocturnal factors were examined by Pearson's correlation method. To identify the contributing role of such factors, multiple stepwise regression analysis was done. A probability of two tailed $\mathrm{p}$-value $<0.05$ was considered statistically significant and all data are expressed as mean \pm SD unless otherwise stated.

\section{Results}

The characteristics and sleep parameters of the patients are shown in table 1 . The mean age was $45 \pm 9$ yrs. Twelve $(37.5 \%)$ patients had a body mass index of $>30$, and none of them had apparent pulmonary dysfunction nor daytime hypoxaemia. All patients had moderate to severe OSA with an average AHI of 53.9 episodes $\cdot \mathrm{h}^{-1}$ ranging 37-69. Severe cardiac arrhythmia and uncontrolled congestive cardiac failure were not found in these patients based on the findings of ECG, echocardiogram and chest radiograph.

Average blood pressure during wakefulness, nonrapid eye movement and rapid eye movement sleep

When compared to awake blood pressure, all variables of average nocturnal blood pressure (systolic, diastolic, mean) in stage 2 NREM sleep were significantly higher, and the average mean blood pressure in the REM period rose more than those of both awake and NREM sleep (fig. 1). Only 4/32 patients showed lower blood pressure in NREM sleep than the awake blood pressure, but they did not have any other distinguishing features compared to the other patients. When hypertensive patients were compared to normotensive patients $(112.7 \pm 17.3$ versus $95.8 \pm$ $16.0 \mathrm{mmHg}$; $=0.01$ ) during NREM sleep. In REM sleep hypertensive patients had greater average blood pressure although the difference was not significant $(119.1 \pm 20.1$ versus $109.4 \pm 20.9 \mathrm{mmHg}$; $\mathrm{p}=\mathrm{NS}$ ).
Table 1. - Characteristics of 32 patients with obstructive sleep apnoea

\begin{tabular}{|c|c|}
\hline Age yrs & $45.1 \pm 9.4$ \\
\hline $\operatorname{Sex} \mathrm{M} / \mathrm{F}$ & $31 / 1$ \\
\hline $\mathrm{BMI} \mathrm{kg} \cdot \mathrm{m}^{-2}$ & $29.6 \pm 4.4$ \\
\hline Patients with history of hypertension & 13 \\
\hline Patients taking antihypertensive drugs & 6 \\
\hline $\mathrm{VC} \%$ pred & $105.4 \pm 15.3$ \\
\hline $\mathrm{FEV} 1 / \mathrm{VC} \%$ & $82.0 \pm 4.3$ \\
\hline $\mathrm{Pa}_{\mathrm{a}, \mathrm{O}_{2}} \mathrm{mmHg}$ & $81.1 \pm 10.2$ \\
\hline $\mathrm{Pa}_{\mathrm{a}} \mathrm{CO}_{2} \mathrm{mmHg}$ & $43.3 \pm 2.5$ \\
\hline $\mathrm{pH}$ & $7.39 \pm 0.0$ \\
\hline$\Delta V^{\prime} \mathrm{E} / \Delta P \mathrm{ET}_{\mathrm{CO}} \mathrm{L}_{2} \mathrm{~L} \cdot \mathrm{min}^{-1} \cdot \mathrm{mmHg}^{-1}$ & $1.8 \pm 0.8$ \\
\hline 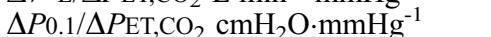 & $0.5 \pm 0.3$ \\
\hline 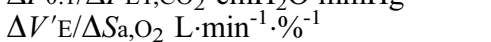 & $0.7 \pm 0.4$ \\
\hline$\Delta P 0.1 / \Delta S_{\mathrm{a}, \mathrm{O}_{2}} \mathrm{cmH}_{2} \mathrm{O} \cdot \%^{-1}$ & $0.2 \pm 0.1$ \\
\hline Apnoea-hypopnoea index episodes $\cdot \mathrm{h}^{-1}$ & $53.9 \pm 16.0$ \\
\hline Lowest $\mathrm{Sa}_{2} \mathrm{O}_{2} \%$ & $50.2 \pm 11.9$ \\
\hline Longest apnoea duration $\mathrm{s}$ & $82.5 \pm 18.7$ \\
\hline
\end{tabular}

Values are expressed as mean $\pm \mathrm{SD}$. M: male; F: female; BMI: body mass index; VC: vital capacity; FEV1: forced expiratory volume in one second; $\mathrm{Pa}_{\mathrm{a}} \mathrm{O}_{2}$ : arterial oxygen tension; $\mathrm{Pa}_{\mathrm{a}} \mathrm{CO}_{2}$ : arterial carbon dioxide tension; $V^{\prime} \mathrm{E}$ : minute ventilation; $P$ ET, $\mathrm{CO}_{2}$ : end-tidal carbon dioxide tension; $P_{0.1}$ : mouth occlusion pressure; $\mathrm{Sa}_{\mathrm{a}} \mathrm{O}_{2}$ : arterial oxygen saturation.

Blood pressure and heart rate in wakefulness and during apnoea and ventilatory periods in sleep

In NREM sleep, when compared to awake mean blood pressure, the mean blood pressure of apnoea periods was found not to be lowered, whereas the mean blood pressure of ventilatory periods was significantly higher. Unlike the blood pressure, the heart rate was significantly lower in apnoea periods and higher in ventilatory periods than the awake heart rate. In REM sleep, the mean blood pressure of ventilatory periods was greater than that in NREM sleep or wakefulness. The heart rate in REM sleep was observed to have a pattern similar to that found in NREM sleep. The mean nadir saturation was lower $(\mathrm{p}<0.01)$ and the apnoea duration was longer in REM sleep $(p<0.01)$ than in NREM sleep (table 2).

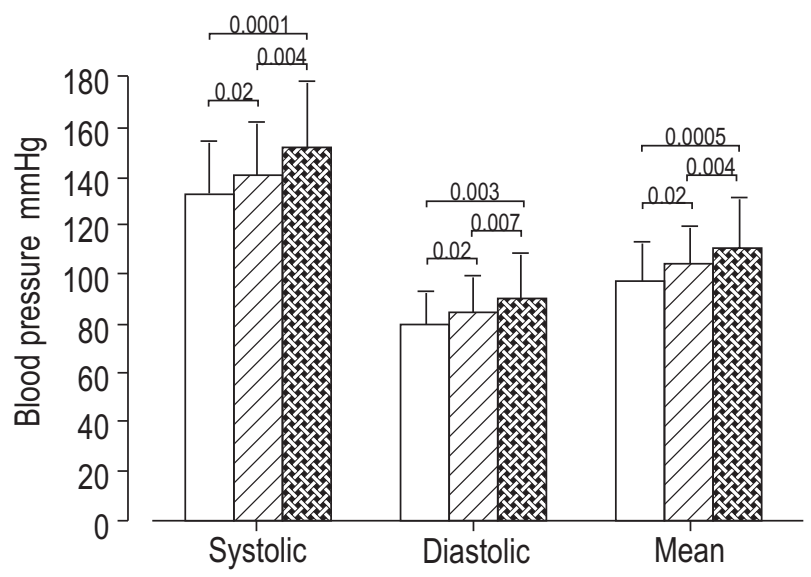

Fig. 1. - Comparisons among awake and asleep blood pressures (nonrapid eye movement (NREM) sleep and rapid eye movement (REM) sleep) in 32 patients with obstructive sleep apnoea. The asleep blood pressure represents the average blood pressure of the whole calculated

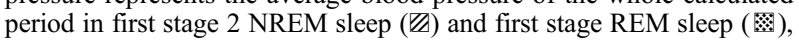
respectively. $\square$ : awake blood pressure. Data are presented as mean \pm SD. 
Table 2. - Blood pressure, heart rate, arterial oxygen saturation and duration of disordered breathing in awake and calculated periods of sleep

\begin{tabular}{|c|c|c|c|c|c|}
\hline & \multirow[b]{2}{*}{ Awake } & \multicolumn{2}{|c|}{ NREM sleep } & \multicolumn{2}{|c|}{ REM sleep } \\
\hline & & $\begin{array}{l}\text { Apnoea } \\
\text { period }\end{array}$ & $\begin{array}{l}\text { Ventilation } \\
\text { period }\end{array}$ & $\begin{array}{l}\text { Apnoea } \\
\text { period }\end{array}$ & $\begin{array}{l}\text { Ventilation } \\
\text { period }\end{array}$ \\
\hline Mean blood pressure $\mathrm{mmHg}$ & $97.0 \pm 15.7$ & $94.5 \pm 15.4$ & $117.5 \pm 17.9^{* *}$ & $102.7 \pm 19.0^{\#}$ & $128.8 \pm 21.9^{* *, \#}$ \\
\hline Heart rate beats $\cdot \mathrm{min}^{-1}$ & $71.4 \pm 9.8$ & $64.5 \pm 8.2 *$ & $76.8 \pm 9.8^{*}$ & $65.6 \pm 7.0^{*}$ & $81.0 \pm 10.7 * *$ \\
\hline $\mathrm{Sa}_{\mathrm{a}, \mathrm{O}_{2}} \%$ & $95.0 \pm 1.2$ & $80.1 \pm 6.2$ & $94.8 \pm 1.1$ & $71.0 \pm 8.6^{\#}$ & $94.3 \pm 1.5$ \\
\hline Duration $\mathrm{s}$ & & $31.8 \pm 7.1$ & $18.7 \pm 5.2$ & $45.2 \pm 9.8^{\#}$ & $19.7 \pm 5.9$ \\
\hline
\end{tabular}

Values are expressed as mean \pm SD. $S \mathrm{a}_{1} \mathrm{O}_{2}$ : arterial oxygen saturation. ${ }^{*}: \mathrm{p}<0.05$ versus awake; ${ }^{* *}: \mathrm{p}<0.01$ versus awake; ${ }^{\#}$ : $<<0.01$ versus NREM. $\mathrm{Sa}_{\mathrm{O}} \mathrm{O}_{2}$ in apnoea period denotes nadir $\mathrm{Sa}_{\mathrm{a}} \mathrm{O}_{2}$ following apnoeic episodes whereas $\mathrm{Sa}_{\mathrm{a}} \mathrm{O}_{2}$ in ventilation period denotes peak $S \mathrm{a}, \mathrm{O}_{2}$ in ventilation periods.

\section{Blood pressure changes in sleep and awake and noc- turnal parameters}

The change in mean blood pressure between apnoea and ventilatory periods was $23.1 \pm 5.4 \mathrm{mmHg}$ and $26.1 \pm 6.9$ $\mathrm{mmHg}$ during NREM and REM sleep, respectively. The mean blood pressure changes from apnoea to ventilatory periods was greater during REM sleep than during NREM sleep. The changes in mean blood pressure were not different in hypertensive and normotensive patients during NREM sleep $(22.3 \pm 6.3$ versus $23.3 \pm 6.0 \mathrm{mmHg}$; $\mathrm{p}=\mathrm{NS})$ or during REM sleep (26.1 \pm 6.8 versus $26.0 \pm 7.3 \mathrm{mmHg}$; $\mathrm{p}=\mathrm{NS})$.

The authors examined the correlation between the mean blood pressure change and the following factors: age, body mass index, daytime arterial blood gases, awake blood pressure, respiratory chemosensitivity, AHI, and nocturnal desaturation. A significant inverse correlation was found between age and the change in mean blood pressure from apnoea to ventilation in NREM sleep $(\mathrm{r}=-0.43, \mathrm{p}=0.01)$ (fig. 2). A similar correlation was also found in REM sleep $(r=-0.54, p=0.01)$ (not shown in the figure).

The mean nadir $\mathrm{Sa}_{2} \mathrm{O}_{2}$ was also found to have an inverse correlation to the mean blood pressure changes from apnoea to ventilation in NREM sleep $(r=-0.42, p=0.02)$ (fig. 2 ), and here again a similar correlation existed in the REM sleep ( $r=-0.56, p=0.01$ ) (not shown in the figure).
No other factors were significantly correlated to the mean blood pressure changes in NREM and REM sleep (table 3).

Multiple stepwise regression analysis was performed with the change in mean blood pressure from apnoea periods to ventilation periods in NREM and REM sleep as a dependent variable and other possible confounding diurnal and nocturnal factors as independent variables. Multiple stepwise regression (mr) values for NREM sleep are shown in table 3. Age and nadir $\mathrm{Sa}_{\mathrm{a}} \mathrm{O}_{2}$ were found to be significant in both NREM and REM sleep.

\section{Discussion}

The main findings were that, in patients with moderate to severe OSA [1] the asleep blood pressures in both NREM and REM sleep were significantly greater than the awake supine blood pressure [2] in REM sleep there is higher blood pressure and greater changes in mean blood pressure from apnoea periods to ventilatory periods [3], the changes in mean blood pressure from apnoea periods to ventilatory periods are inversely correlated to the age and mean nadir arterial saturation in both NREM and REM sleep.

Most studies using $24 \mathrm{~h}$ ambulatory blood pressure monitoring reported only a nondipping of the nocturnal blood pressure, which was still lower than the daytime a)

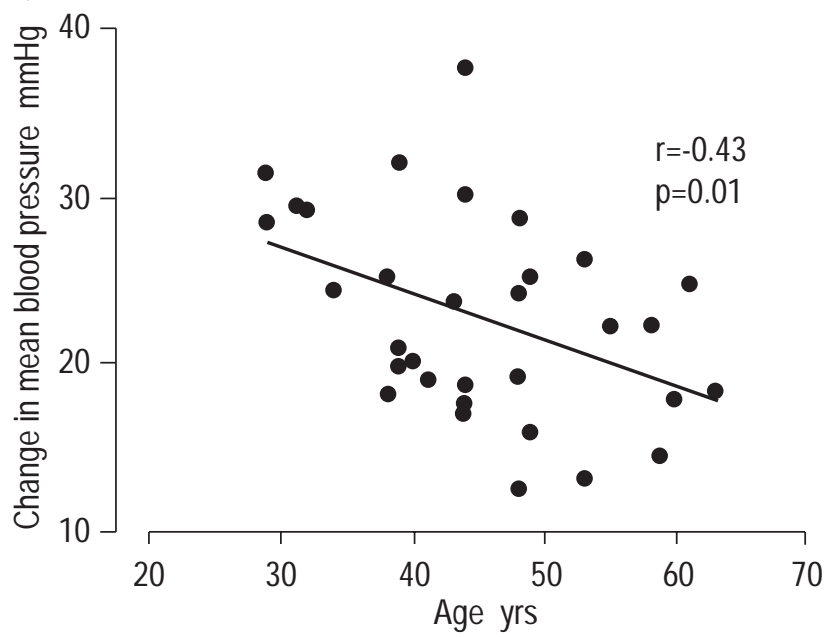

b)

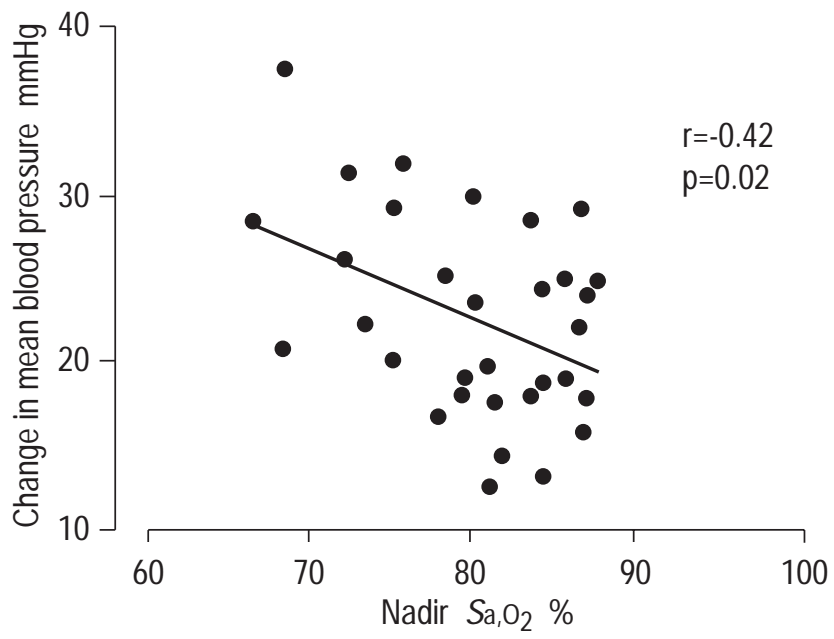

Fig. 2. - Correlation of a) age and $\mathrm{b})$ nadir arterial oxygen saturation $\left(\mathrm{S}_{\mathrm{a}}, \mathrm{O}_{2}\right)$ to change in mean blood pressure from apnoea periods to ventilatory periods during nonrapid eye movement sleep. Lines represent the regression lines. 
Table 3. - Simple linear and multiple stepwise regression analysis (NREM sleep)

\begin{tabular}{|c|c|c|c|c|}
\hline & $r$ & $\mathrm{p}$ & $\mathrm{mr}$ & $\mathrm{p}$ \\
\hline Age yrs & -0.43 & 0.01 & 0.18 & 0.01 \\
\hline $\mathrm{BMI} \mathrm{kg} \cdot \mathrm{m}^{-2}$ & -0.06 & 0.76 & & \\
\hline Awake $\mathrm{Pa}_{\mathrm{a}} \mathrm{O}_{2} \mathrm{mmHg}$ & 0.11 & 0.54 & & \\
\hline Awake $\mathrm{Pa}_{\mathrm{a}} \mathrm{CO}_{2} \mathrm{mmHg}$ & -0.03 & 0.88 & & \\
\hline $\begin{array}{l}\text { Awake mean blood pressure } \\
\mathrm{mmHg}\end{array}$ & 0.03 & 0.85 & & \\
\hline $\begin{array}{l}\text { Hypoxic ventilatory response } \\
\mathrm{L} \cdot \mathrm{min}^{-1} \cdot \%^{-1}\end{array}$ & 0.02 & 0.86 & & \\
\hline $\begin{array}{l}\text { Hypercapnic ventilatory response } \\
\mathrm{L} \cdot \mathrm{min}^{-1} \cdot \mathrm{mmHg}^{-1}\end{array}$ & 0.16 & 0.22 & & \\
\hline $\begin{array}{l}\text { Apnoea-hypopnoea index } \\
\text { episodes } \cdot \mathrm{h}^{-1}\end{array}$ & 0.27 & 0.13 & & \\
\hline Apnoea duration NREM s & 0.25 & 0.12 & & \\
\hline Nadir $S_{\mathrm{a}, \mathrm{O}_{2}}$ (NREM sleep) \% & -0.42 & 0.02 & 0.18 & 0.02 \\
\hline
\end{tabular}

Change in mean blood pressure from apnoea to ventilatory period in nonrapid eye movement (NREM) sleep is regarded as dependent variable. mr: multiple regression analysis; BMI: body mass index; $\mathrm{Pa}_{\mathrm{a}} \mathrm{O}_{2}$ : arterial oxygen tension; $\mathrm{Pa}_{2}, \mathrm{CO}_{2}$ : arterial carbon dioxide tension; $\mathrm{Sa}_{\mathrm{a}} \mathrm{O}_{2}$ : arterial oxygen saturation.

blood pressure [9-11]. But the current study found that blood pressure during sleep was significantly greater than the awake blood pressure in the supine position and quiet state. This discrepancy could be explained by differences in the measuring methods, i.e. ambulatory and finapres, and the effect of posture. Firstly, the ambulatory method with 15-30 min intermittent cuff recordings, which take 20-30 s to complete, is not suitable for catching rapid swings in blood pressure in patients with OSA during sleep [10]. With this method, the blood pressure during the ventilatory periods cannot be measured due to the instability of the blood pressure during these periods, and blood pressures in sleep might be measured only during apnoeic periods, thus underestimating the actual nocturnal supine blood pressure in patients with OSA. Secondly, a comparison between daytime blood pressure and nocturnal blood pressure is limited by postural effects that can alter blood pressure reactivity, i.e. supine blood pressure is lower than standing blood pressure [19]. In this study both awake supine and sleeping blood pressures were measured by the noninvasive continuous monitoring method, which has been documented to provide an accurate estimation of systemic blood pressure when compared to invasive intra-arterial blood pressure monitoring [20]. The measuring hand was carefully maintained in a stable position during the data collecting periods, and any artifactual data caused by hand movement were discarded.

Palatini et al. [8] suggested that hypertensive patients with a night-time blood pressure that was higher than any level of daytime systolic and diastolic blood pressure had a higher degree of target organ damage. That finding is also supported by one recent study which showed that the end-organ damage in treated severe hypertension had a close association with the nocturnal blood pressure [21]. It can be speculated that high nocturnal blood pressure might be a major determinant of cardiovascular complications in patients with OSA since such complications can be found even in OSA patients who are normotensive during the daytime [4].
The finding of a greater blood pressure during NREM sleep than while awake in patients with OSA is consistent with that of DAVIES et al. [22] who showed higher nocturnal blood pressure during $10 \mathrm{~min}$ of NREM sleep than during 10 min while awake in a small number of patients. GARPESTAD et al. [23] reported that the blood pressure in REM sleep with a $78-82 \% S \mathrm{~S}, \mathrm{O}_{2}$ level was significantly higher than that of NREM sleep at the same saturation levels [23]. These investigators also found that, in REM sleep, further desaturation with significant lengthening of obstructive apnoea was accompanied by a significantly higher postapnoeic blood pressure elevation. The current results are also compatible with these findings. One study [24] reported that the cardiovascular reflex function was different in NREM and REM sleep, and the chemoreflex function during REM sleep was found to be more active. This was evidenced in carotid denervated cats developing profound hypotension during REM sleep. This more active carotid reflex probably mediates the higher nocturnal blood pressure through greater hypoxaemia in REM sleep.

The nocturnal (asleep) blood pressure is widely variable in patients with OSA [2]. Increased blood pressure variability constitutes an independent risk factor for cardiovascular diseases [8]. The current authors found that two factors, age and mean nadir $\mathrm{Sa}_{2} \mathrm{O}_{2}$, had a significant inverse correlation with the changes in mean blood pressure from apnoea periods to ventilatory periods. These two factors remained significant by multiple stepwise regression analysis for both NREM and REM sleep. When taking into account both the age and nadir $\mathrm{Sa}_{\mathrm{a}} \mathrm{O}_{2}$ during sleep, $36 \%$ of the variance could be explained. In other words, these two factors account for one-third of the changes in mean blood pressure from apnoea periods to ventilatory periods.

The inverse relation of age to the changes in mean blood pressure could be explained by changes in peripheral vascular resistance. It is now evident that stroke volume and cardiac output are decreased at the termination of obstructive apnoea in spite of the blood pressure elevation [25]. This suggests that vascular resistance is increased at the termination of apnoea. Increased vascular stiffness is universally observed and is one of the most important functional changes associated with aging. This increased vascular stiffness in aged persons would prevent the moment-to-moment fluctuation in the total peripheral vascular resistance in response to various stimuli such as a resumption of the upright posture, blood volume depletion, hypoxaemia, etc. [26]. This mechanism can explain why older OSA patients have less change in peripheral vascular resistance and show less marked blood pressure oscillations during apnoea-ventilation cycles. The inverse correlation of age with the changes in mean blood pressure from apnoea periods to ventilatory periods may provide an explanation for the stronger relation of incidence of hypertension, vascular diseases and mortality with younger age with OSA $[27,28]$.

Hypoxaemia has been recognized as a major factor in the post apnoeic blood pressure elevation. The degree of hypoxaemia was inversely related to the changes in mean blood pressure from apnoea to ventilation in patients with OSA [29]. MотTA et al. [30] reported similar findings, but their results were based on intra-individual differences. A significant relation between hypoxaemia and the blood 
pressure oscillation was still apparent in the current study in spite of wide subject-to-subject differences. Hypoxaemia has also been correlated to sympathetic excitation following apnoea termination, which mediates the postapnoeic blood pressure elevations [31]. Arterial hypoxaemia has both direct and reflex mediated effects on the circulatory system [32]. The direct effect of hypoxia dilates systemic arterioles. This effect would be expected to cause systemic hypotension, but a reflex mediated response to hypoxia typically overrides this direct effect. Thus, the overall effect of systemic hypoxia produces peripheral vasoconstriction and an elevation in blood pressure. Whatever the mechanisms, desaturation in patients with OSA is related to postapnoeic blood pressure elevation.

Recently, a study [33] reported that the mean value of peak blood pressure changes can be predicted by the magnitude of hyperventilation, event length, changes in heart rate, desaturation and the presence of EEG arousal (in order of importance) in patients with mild to moderate OSA. The discrepancy with the current results can be explained by differences in the severity of the disease in the patients studied. In the present study, moreover, most of the patients had EEG arousals in all calculated apnoea episodes since they were of the moderate to severe disease type. That is why the presence or absence of EEG arousals could not be a major determinant for the blood pressure changes in these patients.

There was no significant relation between the preexisting blood pressure and the blood pressure oscillation in either NREM or REM sleep in the current study. This finding can be explained by the weak correlation between different measures of sympathoexcitation associated with apnoea and the resting blood pressure or the presence of hypertension [34]. It was also found that the nocturnal blood pressure elevated parallel to the daytime blood pressure. It could be speculated that OSA patients with daytime hypertension might have high nocturnal blood pressure, resulting in a high average $24 \mathrm{~h}$ blood pressure. From this study the authors could not distinguish whether this nocturnal hypertension is a cause or a result of the daytime hypertension.

Although the patients were not studied for intrathoracic pressure changes in this study, there was no significant difference in the haemodynamic and sympathetic nerve response produced by Muller's manoeuvres at -20 and -40 $\mathrm{mmHg}$ [35]. Thus, the presence of chemoreflex stimulation rather than the magnitude of intra-thoracic pressure determines the magnitude of the neuro-circulatory response to apnoea episodes.

In conclusion, this study has demonstrated that nocturnal blood pressure during sleep is higher than the awake blood pressure, and that an even higher blood pressure is found during rapid eye movement sleep. Two factors correlated with the blood pressure changes are age and level of nocturnal desaturation.

Acknowledgements. The authors thank K. Kikuchi and the nursing staff of First Department of Internal Medicine, Tohoku University Hospital for providing technical assistance, and B. Bell for reading the manuscript.

\section{References}

1. Tilkian AG, Guilleminault C, Schroeder JS, Lehrman KL, Simmonds FB, Dement WC. Hemodynamics in sleepinduced apnea: studies during wakefulness and sleep. Ann Int Med 1976; 85: 714-719.

2. Schroeder JS, Motta J, Guilleminault C. Hemodynamic studies in sleep apnea. In: Guilleminault C, Dement WC, eds. Sleep apnea syndromes. New York, Alan R Liss, 1978; pp. 177-196.

3. Hedner J, Ejnell H, Caidahl K. Left ventricular hypertrophy independent of hypertension in patients with obstructive sleep apnoea. J Hypertens 1990; 8: 941-946.

4. Javaheri S, Parker TJ, Liming JD, et al. Sleep apnoea in 81 ambulatory male patients with stable heart failure. Circulation 1998; 97: 2154-2159.

5. Hung J, Whitford EG, Parsons RW, Hillman DR. Association of sleep apnoea with myocardial infarction in men. Lancet 1990; 336: 261-264.

6. Partinen M, Guilleminault C. Daytime sleepiness and vascular morbidity at seven-year follow-up in obstructive sleep apnea patients. Chest 1990; 97: 27-32.

7. Verdecchia P, Schiallci G, Guerriere M, et al. Circadian blood pressure changes and left ventricular hypertrophy in essential hypertension. Circulation 1990; 81: 528536.

8. Palatini P, Penzo M, Racioppa A, et al. Clinical relevance of night-time blood pressure and of daytime blood pressure variability. Arch Intern Med 1992; 152: 18551860.

9. Suzuki M, Guilleminault C, Otsuka K, Shiomi T. Blood pressure dipping and non-dipping in obstructive sleep apnea syndrome patients. Sleep 1996; 19: 382-387.

10. Khin MH, Young TB, Bidwell T, Palta M, Skatrud JB, Dempsey J. Sleep apnea and hypertension: a populationbased study. Ann Intern Med 1994; 120: 382-388.

11. Pankow W, Nabe B, Lies A, et al. Influence of sleep apnea on 24-hour blood pressure. Chest 1997; 112: 12531258.

12. Shepard JW Jr. Hemodynamics in obstructive sleep apnea. In: Fletcher EC, ed. Abnormalities of respiration during sleep: diagnosis, pathophysiology, and treatment. New York, Grune \& Stratton, 1986; pp. 39-61.

13. Okabe S, Hida W, Kikuchi Y, et al. Role of hypoxia on increased blood pressure in obstructive sleep apnoea. Thorax 1995; 50: 28-34.

14. Ali NJ, Davies RJO, Fleetham JA, Stradling JR. The acute effects of continuous positive airway pressure and oxygen administration on blood pressure during obstructive sleep apnea. Chest 1992; 101: 1526-1532.

15. Rechtschaffen A, Kales A. A manual of standardized terminology, techniques and scoring system for sleep stages in human subjects. Washington DC, National Institutes of Health, 1968; publication No. 204.

16. Ganong WF. Review of medical physiology. Appleton \& Lange, Stamford, 1999; pp. 550-567.

17. Read DJC. A clinical method for assessing the ventilatory response to carbon dioxide. Aust Ann Med 1967; 16:20-32.

18. Rebuck AS, Campbell EJM. A clinical method for assessing the ventilatory response to hypoxia. Am Rev Respir Dis 1974; 109: 345-350.

19. Gellman M, Spitzer S, Ionson G, et al. Posture, place, and mood effects on ambulatory blood pressure. Psychophysiology 1990; 27: 544-551.

20. Parati G, Casadei R, Groppelli A, Rienzo MD, Mancia G. Comparison of finger and intra-arterial blood pressure 
monitoring at rest and during laboratory testing. Hypertension 1989; 13: 647-655.

21. Fagher B, Valind S, Thulin T. End-organ damage in treated severe hypertension: close relation to nocturnal blood pressure. J Human Hypertens 1995; 9: 605-610.

22. Davies RJO, Crosby J, Vadi-Visy K, Clarke M, Stradling JR. Non-invasive beat to beat arterial blood pressure during non-REM sleep in obstructive sleep apnoea and snoring. Thorax 1994; 49: 335-339.

23. Garpestad E, Ringler J, Parker JA, Remsburg S, Weiss JW. Sleep stage influences the hemodynamic response to obstructive apneas. Am J Respir Crit Care Med 1995; 152: 199-203.

24. Guazzi M, Baccelli G, Zanchetti A. Reflex chemoceptive regulation of arterial pressure during natural sleep in the cat. Am J Physiol 1969; 214: 969-978.

25. Garpestad E, Katayama H, Parker JA, et al. Stroke volume and cardiac output decrease at termination of obstructive apneas. J Appl Physiol 1992; 73: 17431748.

26. Ferrari AU. Changes in the cardiovascular system with aging. In: Leonetti G, Cusidi C, eds. Hypertension in the elderly. Developments in cardiovascular medicine. Vol. 17. Dordreht, the Netherlands, Kluwer Academic publishers, 1994; pp. 1-12.

27. Koskenvuo M, Kaprio J, Partinen M, Langinvainio H,
Sarna S, Heikkila K. Snoring as a risk for hypertension and angina pectoris. Lancet 1985; 1: 893-865.

28. Koskenvuo M, Kaprio J, Telakivi T, Partinen M, Heikkila $\mathrm{K}$, Sarna S. Snoring as a risk for ischaemic heart disease and stroke in men. BMJ 1987; 294: 16-19.

29. Van Den Aardweg JG, Karemarker M. Repetitive apneas induce periodic hypertension in normal subjects through hypoxia. J Appl Physiol 1992; 72: 821-827.

30. Motta J, Guilleminault C, Schroeder J, Dement DC. Tracheostomy and hemodynamic changes in sleep-induced apnea. Ann Intern Med 1978; 89: 454-458.

31. Hardy JC, Gray K, Whisler S, Leuenberger U. Sympathetic and blood pressure responses to voluntary apnea are augmented by hypoxemia. J Appl Physiol 1994; 77: 2360-2365.

32. Heistad DD, Abboud FM. Circulatory adjustments to hypoxia. Circulation 1980; 61: 463-470.

33. Morgan BJ, Dempsey JA, Pegelow DF, et al. Blood pressure perturbations caused by subclinical sleep-disordered breathing. Sleep 1998; 21: 737-746.

34. Hedner J. Vascular function in OSA. Sleep 1996; 19: S213-S217.

35. Morgan BJ, Denahan T, Ebert TJ. Neurocirculatory consequences of negative intrathoracic pressure versus asphyxia during voluntary apnea. J Appl Physiol 1993; 74: 2969-2975. 